\title{
Integrating passive cooling techniques for sustainable building performance in hot climates with reference to the UAE
}

\author{
M. A. Haggag \& S. K. Elmasry \\ UAE University, United Arab Emirates
}

\begin{abstract}
On-going development in many parts of the United Arab Emirates has consequences on the urban environment. The use of glazed facades in modern buildings has come with an increased operational cost due to the higher solar gain. However, such strategies have increased in popularity mainly in the local building industry. Thus, improving the ecological performance of buildings and minimizing the impact of urban development on the natural environment are the main concerns for developers and stakeholders in the country at present. These goals have been acknowledged by national and international architectural firms and building developers such as Foster \& Partners, Creative Kingdom and Mirage Mille; which have been incorporating ecological and sustainable approaches in significant projects such as Masdar City in Abu Dhabi, and Madinat Jumeirah in Dubai, where various concepts and techniques have been used to promote energy-efficiency in the buildings and avoid increased cooling loads. The use of passive cooling techniques including natural ventilation, thermal mass, shading devices, and responsive landscaping have been adopted in significant projects to maintain the new vision of the country towards building sustainability. Other cooling techniques such as green roofs and green façades have also been practised recently in a number of projects across the country.

This paper investigates alternative passive strategies for reducing energy consumption in contemporary building design and construction in the UAE. Four techniques are examined in the study: natural ventilation, thermal mass, shading strategy and green walls, and are illustrated in three case studies: Masdar City, Madinat Jumeirah, and Liwa International School in the cities of Abu Dhabi, Dubai and Al Ain respectively. The design and performance of these projects are analyzed and evaluated, with emphasis on passive and sustainable strategies.
\end{abstract}


The study concludes that sustainable building practices in the UAE in terms of cooling load reduction have been acknowledged not only in traditional buildings, but also in a number of significant contemporary projects. The study also demonstrates the potential benefits of passive cooling strategies to minimize the negative impact on the natural environment, and finally it proposes guidelines for architects and developers on passive design and construction strategies as pertains to the UAE environment.

Keywords: low energy building performance, green wall, passive cooling techniques, sustainability, UAE.

\section{Introduction}

Following the 1971 federation and the discovery of oil, fast urban development completely changed the character of traditional cities of the UAE. The country is characterized by scarce rainfall and high temperature, humidity and sunshine. Summer daytime temperatures range from $35^{\circ} \mathrm{C}$ to $50^{\circ} \mathrm{C}$. Winter daytime temperatures range from $25^{\circ} \mathrm{C}$ to $35^{\circ} \mathrm{C}$ [1]. The traditional urban pattern of the UAE cities was the result of the hot and humid climate. High-density buildings were constructed close together, creating narrow alleys, which were shaded most of the day. These alleys tended to run from north to south and ended at the creek, permitting the prevailing winds to pass through. The main traditional architectural features are the courtyard and the wind-tower. Most rooms look inward with a shaded veranda overlooking the courtyard, which provides a reservoir of cool air. Wind-towers are unique and elegant architectural elements, acting as conduits for trapped air to be directed to the rooms beneath. A typical traditional architectural pattern is presented in the old district of Bastakiya in Dubai, as shown in figure 1.

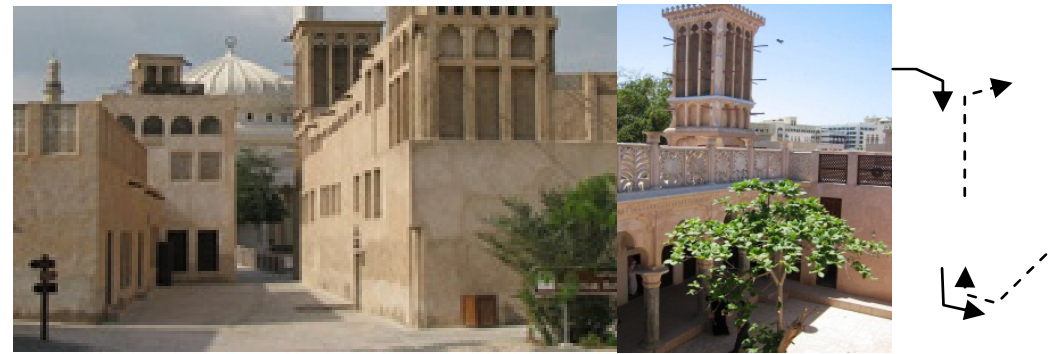

Figure 1: Traditional architectural pattern of Bastakiya district (narrow alleys, courtyards and the wind-towers).

The modern urban pattern (see figure 2), which was established during the second half of the 20th century, was concerned with highly specialized building techniques. A number of enormous mega-projects have been developed mainly in Abu Dhabi and Dubai, including Burj Khalefah (the world's tallest tower located in Dubai); Madinat Jumeirah (the largest modern resort in Dubai); AlRaha Beach; Saadiyat Island; and Masdar City in Abu Dhabi. Although UAE is 
one of the hottest countries in the Gulf region, the use of glazed façades has increased in popularity, usually with increased operational costs and energy consumption due to the higher solar gain, and negative environmental impacts. Minimizing this impact on the natural environment and the efforts to improve the ecological performance of any project are the main concerns of sustainable building development during and after the construction period [2]. Thus, energy efficiency, healthy environment, and the protection of biodiversity are now the key issues in urban development in many cities such as Abu Dhabi and Dubai. How can cities with rapid urban development sustain their building practices in terms of energy consumption?
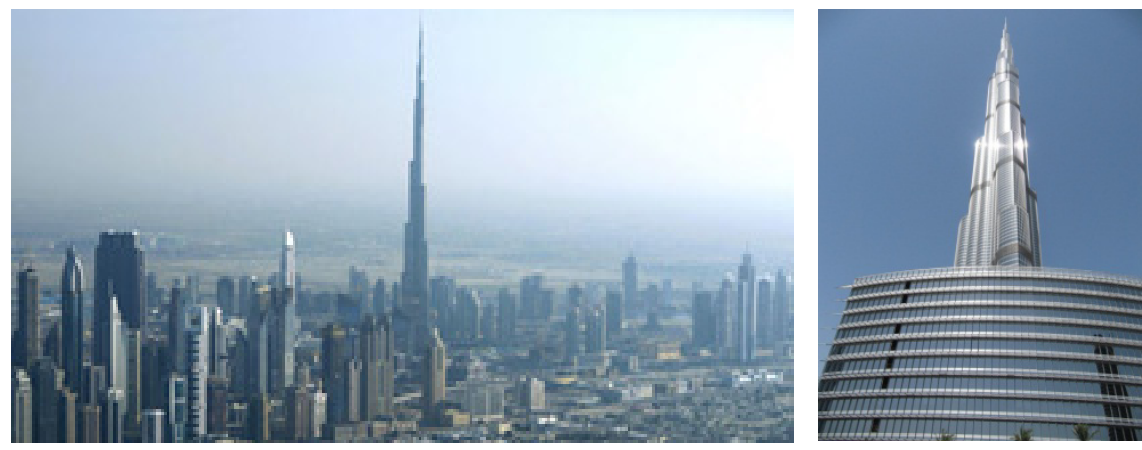

Figure 2: New urban and architectural patterns of Dubai. Burj Khalefah.

\section{Sustainable development and passive cooling strategies}

Sustainable development refers to a socio-ecological process characterized by the fulfilment of human needs while maintaining the natural environment. Sustainable Building is an approach to architectural design that emphasizes the place of buildings within both local ecosystems and the global environment. It is the practice of increasing energy efficiency, while reducing building impact on human health and the environment through better siting, design, construction, operation and maintenance [3].

Effective sustainable buildings require careful attention to the full life cycle impact of resources. Building materials, one of the key issues of sustainable architecture, should be "green" and obtained from local sources including rapidly renewable plant materials like palm fronds and bamboo, coral stone, recycled material, and other products that are reusable and renewable. Reducing energy loads is another issue for sustainable buildings. It is important to orient the building to take advantage of cooling breezes in a hot climate, and sunlight in a cold climate. To minimize the energy loads, passive solar design can be effective. Masonry building materials with high thermal mass are efficient for retaining the cool temperatures of night throughout the day. Moreover, buildings are often designed to capture cool winds. Passive solar design relies on the integration of a building's architecture, materials selection and mechanical 
systems to reduce heating and cooling loads, taking into consideration local climatic conditions to create climate-responsive, energy conserving structures that can be powered with renewable energy resources [4]. The most important step in the passive cooling process is to develop an energy efficient building envelope to minimize heat gains and catch cooling breezes, for example: orienting more windows to the north; incorporating adequate shading to prevent solar radiation; incorporating thermally massive building materials; suitable insulation; high performance glazing to reduce heat gain and admit natural light. Landscape and outdoor spaces are also important passive cooling strategies. Vegetation, green roofs, green walls, water ponds and fountains are efficient cooling techniques. In the UAE, where cooling is a primary concern, much can be done to capture natural breezes to keep buildings cool. Combining proper ventilation, courtyards, wind-towers, shading devices, thermal mass, vegetation and insulation can reduce energy loads for cooling.

A natural passive cooling system is an option for sustaining a cool building and reducing air conditioning costs. About $30 \%$ of the unwanted heat comes in through the building roof, and more than $40 \%$ through windows [5]. To minimize the effect of radiant energy, a reflective waterproof coating and installation of a radiant barrier on the underside of the roof are essential. This can reduce heat gains by about 25\% [5]. Light-coloured surfaces effectively reflect most of the heat. Reflective window coatings can also reduce the heat gain by about $35 \%$ [6]. Sun-coating films can reflect as much as $80 \%$ of the incoming sunlight [5].

Shading, insulation, plantation, and landscaping are good strategies to block the heat. In most cases, shading can reduce indoor temperatures by $10^{\circ} \mathrm{C}[5]$. Effective shading can be provided by well-placed trees and shading devices. Exterior shading is more effective than interior as it blocks sunlight before it enters windows. Insulation helps seal and protects buildings against the heat. The upper roof is the most important place to start insulating. Wall insulation is not as important as roof insulation because of differences in outdoor temperature between roof and wall. Floor insulation has little and sometimes no effect on cooling.

Natural ventilation helps remove heat and maintains indoor temperatures close to outdoor temperatures. This strategy only works when the inside temperature is higher than outside temperature. In hot climates, a building designed for passive cooling would be as open as possible to ensure the maximum possible cross ventilation [7]. East and west walls should have a minimum of windows in order to exclude the low angle sun-rays. However, north and south walls should have enough windows to allow cross ventilation. A thermal chimney can be used to ensure ventilation by creating a warm zone with an exterior outlet. The wind-tower is another dramatic device for using the cooling potential of the available breezes. The courtyard is a common architectural feature and is considered as a microclimate modifier, which improves thermal comfort conditions in the enclosed as well as the attached built environment. The courtyard provides thermal environmental conditions through its design concept, forms and heights. During the day, the shading arcades, trees, 
and vegetation protect the building from direct solar gain, and the cool mass in the courtyard floor absorbs a significant amount of solar radiation. A massive courtyard floor surrounded by a building provides cooling, primarily by radiation to the cool, clear night sky. The night time radiation cools the mass and the air trapped in the courtyard.

\section{Madinat Jumeirah, Dubai}

Madinat Jumeirah (City of Jumeirah), one of the largest resorts in Dubai, was constructed in 2004 in the heart of new Dubai. It reflects the rich cultural heritage of Dubai and resembles an ancient Arabian architectural style. Madinat Jumeirah comprises two 5 stars hotels (Al-Qasr and Mina Al-Salam), courtyard summer houses (Dar Al-Masyaf), a traditional market and cultural village, a conference centre, and recreational facilities. Nearly $4 \mathrm{~km}$ of waterway runs through the entire city. Madinat Jumeirah forms a virtual island looking down upon wind-towers, courtyard houses, pools, meandering waterways with traditional water taxis, and a private beach.

The outstanding architectural concept of Madinat Jumeirah was based on a theme of old Dubai in a luxurious context. It was designed by an international multidisciplinary design firm (Creative Kingdom) and developed by Mirage Mille. The project was designed and built in an ecological and resource-efficient manner. The combination of green design techniques used in the project will not only reduce energy consumption and environmental impact, but also reduce running costs, create more pleasant indoor spaces, improve occupants' health, and reduce pollution and legal liability. Various concepts and techniques were used to design and develop energy-efficient buildings and cooling load avoidance in Madinat Jumeirah. Design strategies that minimize the need for mechanical cooling systems were adopted, including proper shading, natural ventilation, thermal mass, careful siting and orientation decisions, and good landscaping.

\subsection{Shading devices}

Fixed shading devices are installed mainly on the south-facing windows. They are carefully designed to allow the sun to penetrate only during determined times of the year. In the summer, the overhangs block the high sun; however they allow the low winter sun to enter the windows (see figure 3).

\subsection{Vegetation and landscaping}

Trees and vegetation are properly located and used for shading. Vegetation, pools and canals around buildings contribute to an evaporative cooling strategy. Plants improve aesthetically the surrounding spaces of buildings and decrease ambient air temperature. Based on an analytical study which was carried out by the authors, plantations can reduce the air temperature nearby buildings by up to $5^{\circ} \mathrm{C}[8]$ in the surrounding areas. The application of plants around buildings and 


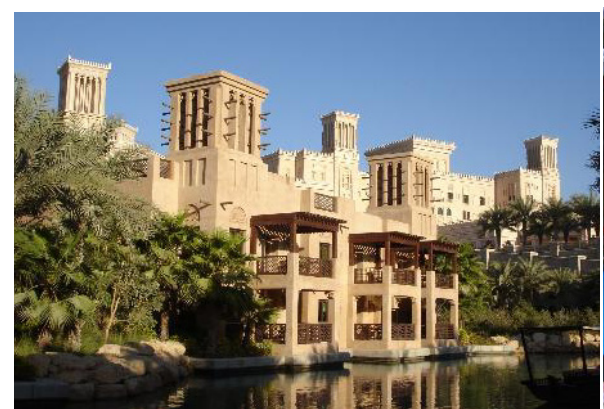

Dar Al-Masyaf (courtyard summer houses).

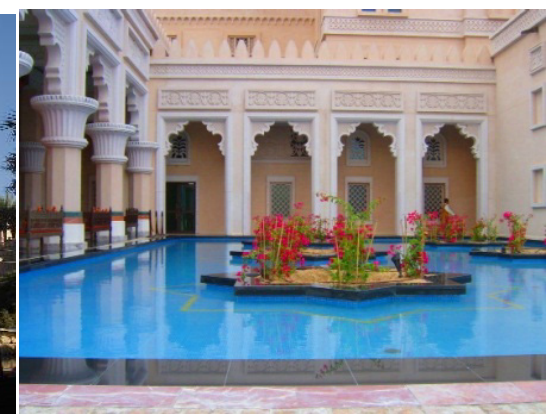

Al-Qasr Hotel - inner court.

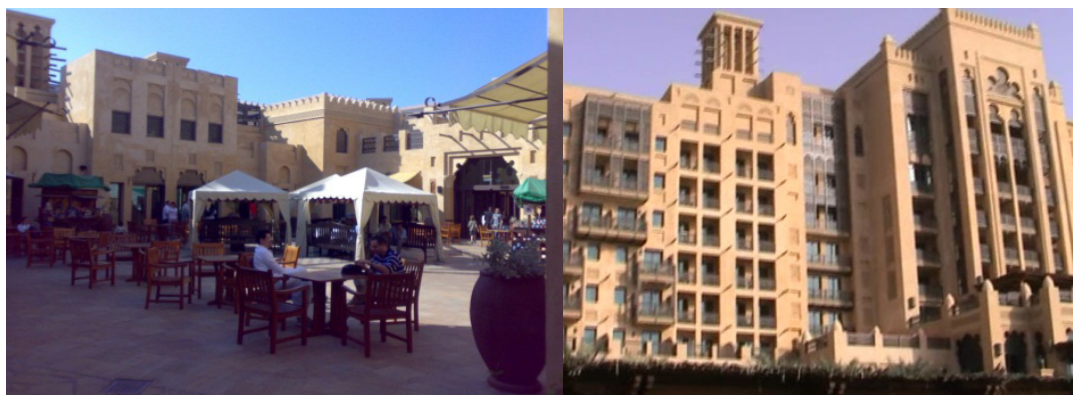

Jumeirah traditional market.

Mina Al-Salam Hotel.

Figure 3: The use of passive cooling strategies in Madinat Jumeirah (Shading devises, vegetation and landscaping, wind-towers, and courtyards).

radiation and thus reduce energy consumption in buildings. This application can act as a protective barrier which provides buildings with better solar protections that can reduce the effect of the external load and the cooling need.

\subsection{Natural ventilation: wind-tower and courtyards}

Buildings in Madinat Jumeirah were designed to take advantage of natural ventilation which uses the passive stack effect and pressure differential to bring fresh cooling air through buildings with limited or no mechanical systems. This strategy has been adapted by incorporating different means of outdoor air intake, including operable windows. East and west windows are limited and the majority of them are north-facing windows to reduce direct solar gain. The wind-tower has been used in Madinat Jumeirah to increase the air flow in buildings (see figure 3). Other features include fresh air inlets located near floor level, use of atriums, and courtyards that have been adapted to enhance the stack effect and to speed the indoor air flow. As shown in figure 3, courtyards have been used not only to improve indoor comfort but also to provide a pleasant outdoor environment. They help achieve desirable thermal environmental conditions not by mechanical devices but by architectural design (form, materials, floor covers and landscaping). 


\subsection{Thermal mass}

The building skin, which separates the interior spaces from the outdoor environment, is an important concept for energy efficiency and a major factor in determining the amount of energy used in buildings. External insulated dense materials (opaque mass wall) like concrete, bricks, and other masonry covered with plaster have been used in Madinat Jumeirah in passive design way to absorb, store, and re-release thermal energy. This strategy increases comfort and reduces energy consumption by moderating internal temperatures by average day/night extremes. Building forms, volume, and orientation also have significant impacts upon the efficiency of the building skin in Madinat Jumeirah. Openings are limited and mainly directed to the north. The comparison analysis of the performance of various building skins, which was carried out by Straube, proved that the opaque mass wall has the lowest thermal transmission coefficient (U-value), and the highest sound control [9].

\section{Masdar City, Abu Dhabi}

Masdar City was initiated in 2006 as one of the most sustainable cities in the World. It is being constructed $17 \mathrm{~km}$ away from the centre of Abu Dhabi, and targeted to a 2016 completion date. Designed by Norman Foster, Masdar city is planned to be the first city where carbon emissions are zero, waste is converted to energy, desalinated water production reduced by $75 \%$, and $80 \%$ of water will be recycled and powered by $100 \%$ renewable energy [10]. The city includes Masdar Institute of Technology, laboratories and research facilities, commercial spaces for energy related companies, and a science museum. The city will host 50,000 people, in addition to 40,000 commuters. Masdar, as a car-free city, will be linked to the centre of Abu Dhabi by a new mass transit railway [10]. Electric buses and personal rapid clean-energy vehicles are provided as inner city transport system, while a light railway is proposed to link the city with the metropolitan area. Most private vehicles are to be kept in parking lots located at the edge of the city. The city is designed to be self-sustaining; therefore, the surrounding land outside the city will contain photovoltaic and wind farms, research fields and plantations, desalination plant, water treatment plant, a recycling centre, and visitors' parking.

The outstanding architectural concept of Masdar City was based on traditional planning ideologies, characterized by narrow shaded alleys, courtyards, and wind-towers (figure 4). The city was designed in an ecological and resourceefficient manner. The street grid pattern is oriented on a southeast-northwest axis to catch the cooling breezes, provide shading, and reduce thermal loads on building façades. The combination of the applied green design techniques will not only reduce energy consumption and environmental impact, but also reduce running costs, create more pleasant spaces, and improve occupants' health. To produce lower greenhouse gas emissions, a variety of renewable energies are considered within the city development [10]. These technologies include: i) Solar Energy: the use of photovoltaic technology, as a solar power system is planned 


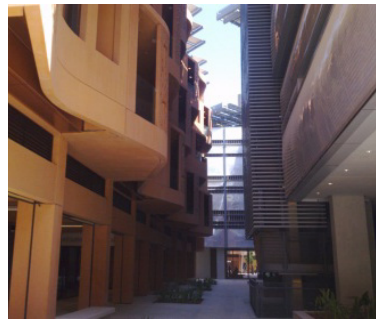

Narrow shaded alleys.

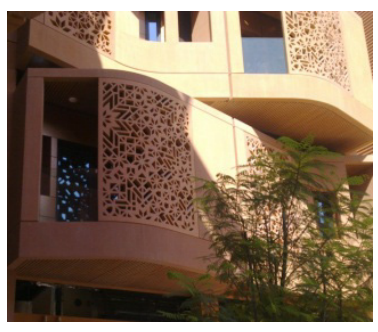

Shading devices and thermal mass.

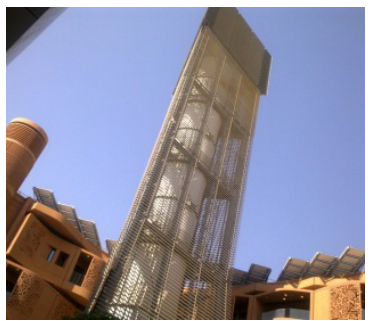

Wind-towers and courtyards.

Figure 4: The use of passive cooling strategies in Masdar city.

to provide almost $50 \%$ of the electricity required. ii) Wind Power: large-scale wind farms are proposed and will be connected to the city electric power transmission network. iii) Concentrating Solar Power: a field of mirrors and tracking systems is provided to focus a large area of sunlight onto a specific small beam. The concentrated light is used as a heat source for a conventional power station. iv) Geothermal Heat: a heating and/or cooling system that uses the earth's ability to store heat in the ground or water thermal masses. v) Waste-toEnergy: the process of creating energy in the form of electricity from the controlled combustion of municipal solid wastes. Water management has also been planned in an environmental manner. A solar-powered desalination plant will be constructed to provide the city with a water supply. About $80 \%$ of the water used will be recycled and reused for irrigation and other domestic uses. It is also planned to reduce the city's waste to zero [10]. Biological waste will be used as fertilizer; municipal solid wastes will be utilized as an additional power source; and industrial wastes will be recycled. Construction waste is heavily reused in the building industry. Waste steel, concrete, plastics, and timber are collected in a Materials Recycling Centre for processing and use in new buildings.

Various passive cooling strategies have been applied to the architectural concept of Masdar City; buildings are designed in an energy-efficient manner. Intelligent shading devices are used to reduce heat gain on building façades, while increasing natural light. Pedestrian walkways are shaded with retractable awnings which can be opened at night to catch the cooling breezes. Modern wind-towers are located in the main piazzas to collect cooler upper breezes and direct them downward to the public spaces and courtyards (see figure 4).

Building façades are designed in an energy-efficient way that accommodates change in the environment and in occupant needs; using self-regulating thermal protection and solar control measures, using natural, renewable energy sources. Two strategies have been taken into consideration in designing building façades: keeping cooling losses low, and avoiding undesired heat gains through solar radiation. This has been achieved by the number of glazing skins incorporated in the design and the use of solar control devices. Some buildings façades are covered with cushion-shaped ETFE (Ethylene Tetrafluoroethylene) backed by 
reflective foil to develop an intelligent façade with low thermal mass. This strategy limits heat-gain and reduces cooling need inside the buildings [11].

The above strategies have an ecological and environmental significance since they reduce the global greenhouse effect by limiting carbon emissions; and reduce the investment and operational cost of building technology.

\section{Liwa International School, Al-Ain}

Liwa International School (LIS) is sited in the south west end of Al-Ain City in the inner desert oasis of the UAE. The school building was constructed in 1992 and converted from conventional to sustainable green building in 2010. As a member of the global network of UNESCO affiliated schools, LIS has participated in the World Future Energy Summit 2010 with a sustainable green building project. This project aimed to reduce energy consumptions and increase energy efficiency in buildings by adopting green wall technique, using solar energy, and recycling grey water. As part of an experimental work which was carried out by the authors in 2010 [8], LIS was selected as a case study to investigate the performance of the integrated building façade with the application of green wall system in the hot climate of Al Ain city.

A vegetated living wall was installed on the building façades as illustrated in figure 5. Data gathering took place immediately after installation during October and November when temperatures drop significantly in Al Ain. Orientations of the building facades were taken into consideration as well as the times when the sun has a perpendicular azimuth on the facades. Using temperature data loggers, measurements were taken on and around the internal and external surfaces of wall as well as the ambient temperature on both sides of the wall. Temperature measurements were taken in two situations: i) locations with the vegetated walls installations, and ii) locations without vegetated wall installations.
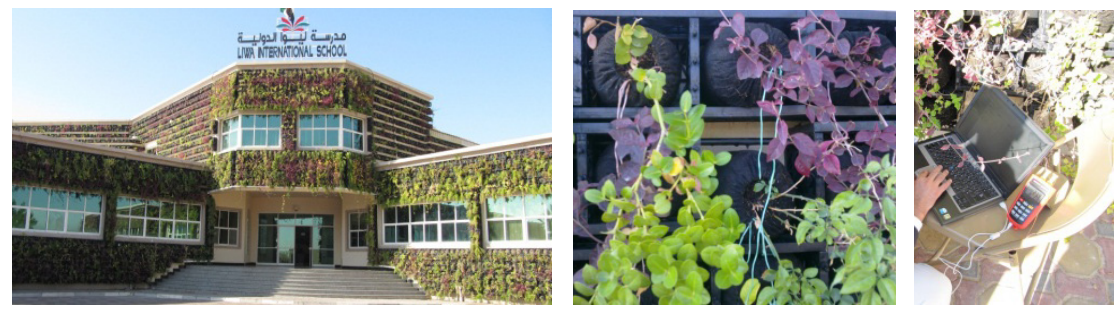

Figure 5: Liwa International School, Al-Ain - green wall application.

To analyse the thermal performance of the green façade, the temperatures on the indoor and outdoor surfaces and ambient were recorded to investigate: i) the outdoor microclimate; ii) the reduction of wall temperature; iii) resistance to heat flow; iv) the reduction of cooling need. Figure 6 shows a difference of temperature up to $2.5^{\circ} \mathrm{C}$ in the last week of October. (The larger temperature difference is explained by local heat loss due to evaporation of the planting 


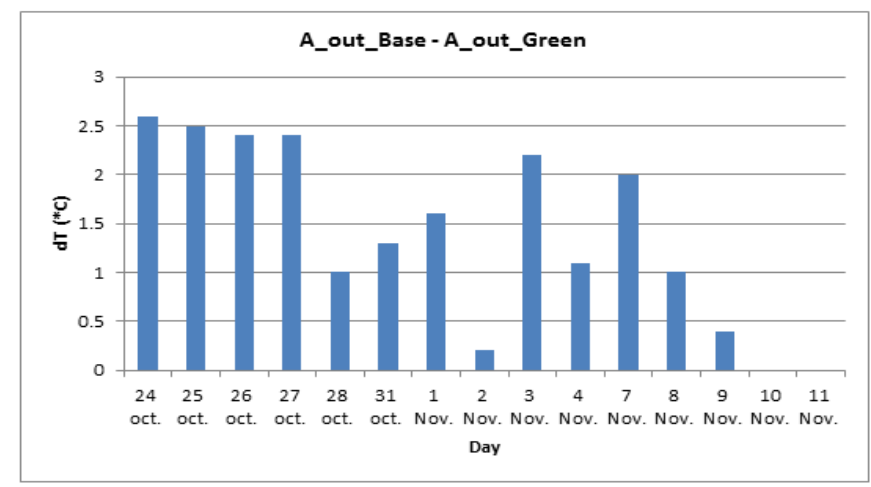

Figure 6: The temperature difference on the outdoor ambience of green and bare façades to determine the microclimatic effect of the green façade.

irrigation system and local convection due to wind flow patterns due to the thermocouples being located very close to the vegetation).

To determine the local cooling effect produced by the green façade on the external wall, the external surface temperature of the green façade is compared with the corresponding external surface temperature of the bare façade, as shown in the figure 7 . The green facades maintained a lower temperature which was higher at the start of the experiments and continued to decrease with few exceptions. The decreased temperature on the green facades was achieved by: i) Decreased heat gain of the green façade compared to bare façade due to incident radiations being blocked by the vegetation leaves, soil mass, and the assembly carrying the plants; ii) The evaporative cooling caused by the irrigation water to the plants; and iii) heat resistance due to low thermal conductivity of the plants compared to the masonry wall acting as heat insulators to the ambient heat gain by the wall.

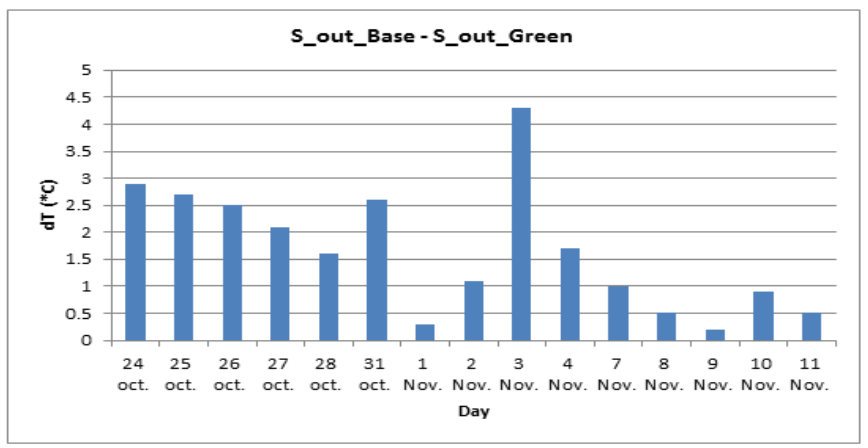

Figure 7: The cooling produced by the vegetation on the external wall of the green façade. 


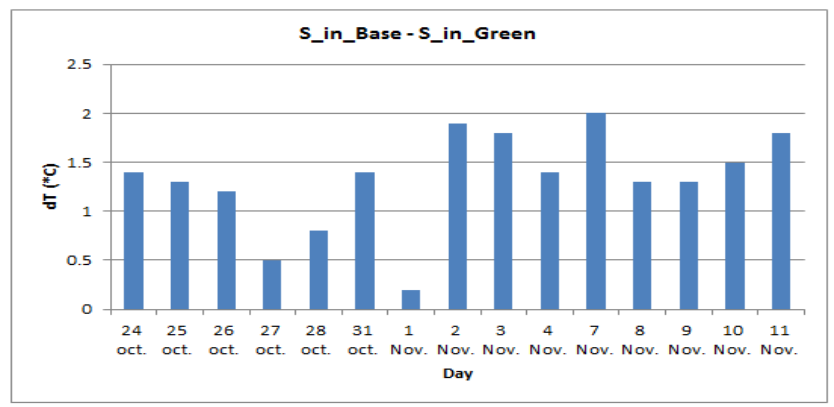

Figure 8: The resistance to heat flow offered by the green facade into the inside wall surface.

The green facade reduces heat flow from the external surface to the internal surface of the masonry wall shown by the temperature difference between the internal wall surfaces of the green and bare façade in figure 8 .

The effect of the green façade on the cooling demand reduction is determined by comparing indoor ambient temporaries obtained with the green and bare facades as shown in figure 9. The lower indoor ambient temperature decreases the cooling demand of the building. The lower temperature reduction can be attributed to the fact that: i) The green facade was just at the stage of inception and was not mature enough to produce a thick layer of vegetation to block substantially direct and diffused radiations and the ambient heat gains which resulted in higher indoor surface and ambient temperatures; ii) The measurements were taken late in the summer which further reduced the cooling effect due to decreased ambient temperatures. This would have led to an erroneous measurement procedure as it neglected the thermal mass effect and the time delay for the cooling effect to pass through the façade to produce reduced temperatures indoors. These mentioned problems will be addressed by: i) Taking measurements when the plants have grown enough to provide heat insulation and radiation sink; ii) Measuring data over a year for the whole day to see the effect

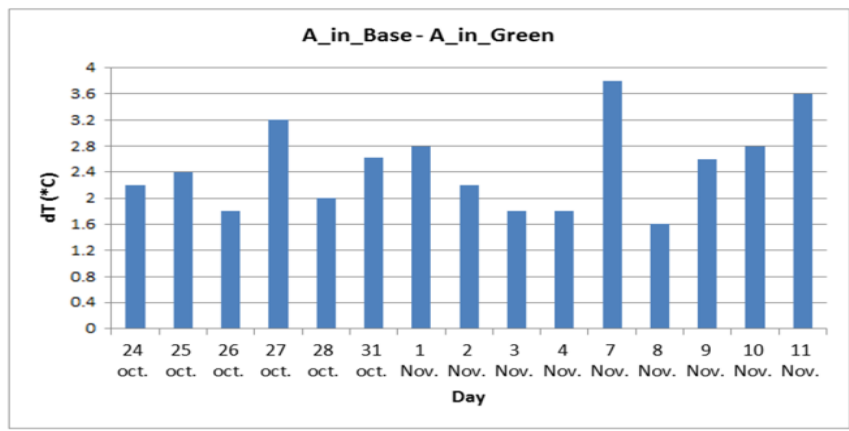

Figure 9: Comparison of indoor ambient temperatures of the green and bare facades as an indicator to cooling load reduction. 
of the seasonal variation, thermal mass and time lag of cooling effect to transfer into indoors; and iii) Taking measurements in the hot summer months when the outdoor temperatures are extreme and the green façade will make a difference.

\section{Conclusion}

Recent on-going developments in UAE have consequences on the urban environment. Minimizing the impact of urban development on the natural environment and the trend to improve the ecological performance of buildings are the main concerns of the sustainable building practices in the country. These ideologies have been acknowledged by national and international architectural firms to develop new projects that are energy efficient by incorporating ecological and sustainable approaches in their designs.

The development of Madinat Jumeirah and Masdar City is a significant sustainable development that aims to reduce cooling loads and increase occupants' comfort. Various passive cooling strategies have been used to develop energy-efficient buildings and cooling load avoidance. The use of natural ventilation, thermal mass, proper shading, careful siting and landscaping have been adopted in these projects. Other cooling techniques have been used, including wind-towers and courtyards. The use of green wall as a passive technique was successfully adopted not only in the new construction projects but also in the old building façades as applied to Liwa International School at Al-Ain City. The combination of the passive cooling strategies will not only increase energy efficiency in buildings and reduce environmental impact, but also increase sound insulation and create more pleasant indoor spaces and air quality improvements.

\section{References}

[1] www.datadubai.com/technical-info

[2] Botta, M. 2005, Towards Sustainable Renovation Three Research Projects. KTH, Stockholm.

[3] Wheeler, S. and T. Beatley, 2004, The Sustainable Urban Development, New York.

[4] Brown, G. and M. Dekay, 2006, Sun, Wind, and Light: Architectural Design Strategies, Wiley, London.

[5] www.empowementzon.com

[6] Vallero, D. and C. Brasier, Sustainable Design: The Science of Sustainability and Green Engineering, John Wiley \& Sons, 2008.

[7] www.arch.hku.hk

[8] Haggag, M. et al, 2010, Integrating Advanced Facades for Low-Energy Building Performance: Intelligent Design Criteria for the UAE, Individual Research Project, UAEU

[9] Straube, F. and R. Straaten, The Merit of Double Facades for Office Buildings in Cool Humid Climates, University of Waterloo, 2001.

[10] Masdar Initiative and Masdar Development. www.masdaruae.com.

[11] The global centre of future Energy, Masdar City. 